RESEARCH NOTE

\title{
FAILED ATTEMPT OF CRYPTOSPORIDIUM ANDERSONI INFECTION IN LAMBS
}

\author{
Martin Kváć $^{1,2}$, Oleg Ditrich ${ }^{1}$, Martin Kouba $^{2}$, Bohumil Sak $^{1}$, Jiří Vítovec $^{2}$ and Dana Květoňová ${ }^{1}$ \\ ${ }^{1}$ Institute of Parasitology, Academy of Sciences of the Czech Republic, Branišovská 31, 37005 České Budějovice, Czech \\ Republic; \\ ${ }^{2}$ Department of Anatomy and Physiology of Farm Animals, Faculty of Agriculture, University of South Bohemia, Studentská 13, \\ 37005 České Budějovice, Czech Republic
}

\begin{abstract}
Four lambs 4 months old were inoculated with Cryptosporidium andersoni oocysts (bovine isolate) in a dose of $5 \times 10^{6}$ per animal followed later by $1 \times 10^{7}$ oocysts per animal. No animal shed Cryptosporidium oocysts during 56 days post infection, no lamb showed clinical symptoms of cryptosporidiosis and no macroscopic changes were detected in the abomasum immediately after autopsy. Histological examinations did not demonstrate the occurrence of Cryptosporidium in the abomasum and other selected organs.
\end{abstract}

Cryptosporidium andersoni (Apicomplexa: Cryptosporidiidae) was described in 2000 by Lindsay et al. (2000). The description was based on molecular differences that were found between murine and bovine isolates of cryptosporidia in the stomach of mouse, respective cattle. The name $C$. muris remained for the murine isolates, while a new species, $C$. andersoni, was described from so-called C. muris-like bovine isolates. The typical hosts of $C$. andersoni are cattle (Bos taurus) but $C$. andersoni can also infect the Bactrian camel (Camelus bactrianus), bobak marmot (Marmota bobac) and European wisent (Bison bonasus) (Ryan et al. 2003). Koudela et al. (1998) successfully infected Mongolian gerbils (Meriones unguiculatus) with $C$. muris (bovine isolate, probably $C$. andersoni) and Pospischil et al. (1987) described abomasal cryptosporidiosis in four mountain gazelles (Gazella gazella cuvieri).

Cryptosporidium andersoni infection has also been described in HIV positive patients (Guyot et al. 2001). Anderson (1991) experimentally verified that oocysts morphologically similar to $C$. muris isolated from the faeces of a Bactrian camel were infective for mice, although oocysts designated as C. muris from cattle faeces were not and Fayer et al. (1991) have previously described isolates of $C$. muris from a Bactrian camel which did not infect calves. Cryptosporidium andersoni and C. muris (bovine isolate) are not found to be infective for laboratory outbred, inbred, immunocompetent and immunodeficient mice and rats and are also non-infective for common and bank voles, rabbits, goats and guinea pigs (Anderson 1991, Koudela et al. 1998, Lindsay et al. 2000, Sréter et al. 2000).

The spontaneous infection of $C$. andersoni in sheep has not been described previously. The infection of sheep with $C$. parvum was first reported by Meutin et al. (1974). Chalmers et al. (2002) described a novel isolate of Cryptosporidium from sheep which had different Cryptosporidium oocyst wall protein (COWP) PCR product sequences in comparison with C. andersoni (difference in 20.85 bases [bp] per $100 \mathrm{bp}$ ) and with $C$. parvum (genotype 2) (in $8.40 \mathrm{bp}$ per $100 \mathrm{bp}$ ). An attempt to infect lambs with bovine isolate of $C$. andersoni

Address for correspondence: $M$. Kváč, Institute of Parasitology, Academy of Sciences of the Czech Republic, Branišovská 31, 37005 České Budějovice, Czech Republic. Phone: +420 387775 419; Fax: +420385310 388;:E-mail:kvac@centrum.cz and evaluation of these animals as possible model hosts of this parasite are described in the present sudy.

The oocysts of $C$. andersoni were obtained from a Holstein bullock 146 days old. The bullock, one of a group, was kept in a stall on deep straw bedding. The partial 18S rRNA sequence (434 bp) of our Cryptosporidium isolate was $99 \%$ similar to the $C$. andersoni sequence (AB089285) (Satoh et al. 2003) from the GenBank. Six Merinolandschaft $\times$ Charollais crossbred $31 / 2$ months old lambs purchased from a commercial farm (1. Jihočeská zemědělská společnost a.s., Czech Republic) were used in all experiments. The experimental group consisted of 4 lambs and the control group consisted of 2 lambs. Both groups were housed in stalls of the University of South Bohemia in České Budějovice, Czech Republic. Viability of cryptosporidium oocysts was tested by propidium iodide staining (Dowd and Pillai 1997). After 2 weeks of daily monitoring for the presence of Cryptosporidium oocysts with negative result, the experimental group were inoculated with a dose of $5 \times 10^{6} \mathrm{C}$. andersoni oocysts in $10 \mathrm{ml}$ of sterile water and the control group with $10 \mathrm{ml}$ of sterile water. Since no animals shed Cryptosporidium oocysts by day post infection (DPI) 28 , the experimental group was re-inoculated with $10 \times$ $10^{6} \mathrm{C}$. andersoni oocysts per $10 \mathrm{ml} /$ animal while the control group received $10 \mathrm{ml}$ of sterile water. All animals were examined for the presence of oocysts in faeces using the modified Ziehl-Neelsen (ZN) staining method (Henriksen and Pohlenz 1981) and modified Miláček-Vítovec staining (MV) (Miláček and Vítovec 1985) each day. All experimental animals were euthanized with a thiopental overdose on DPI 56 (primary infection) and autopsied. Immediately after autopsy, tissue samples were prepared for histology and scanning electron microscopy (SEM). Purified oocyst samples were prepared and examined for the presence of $C$. andersoni using histological, SEM and molecular methods as previously described by Kváč and Vítovec (2003).

Animals from both groups were negative for Cryptosporidium oocysts in the 2-week-period before inoculation, although faeces of all animals were positive for Giardia intestinalis cysts and Eimeria spp. oocysts (natural infections). No lambs shed Cryptosporidium oocysts by DPI 28 (primary infection), which was longer than the prepatent period ( 25 days) experimentally verified in a calf (Enemark et al. 2002). All experimental lambs were reinfected with Cryptosporidium oocysts but all faecal staining proved negative during the length of the experiment.

No lambs showed clinical symptoms of cryptosporidiosis in subsequent autopsy, no macroscopic changes were detected in the abomasum or other examined organs (oesophagus, rumen, reticulum, omasum, duodenum, proximal, central and distal jejunum, ileum, caecum, colon, rectum, large biliary ducts at the porta hepatis, ductus choledochus, gall bladder, liver, pancreas, lungs and spleen), and histological exami- 
nation proved negative for the occurrence of Cryptosporidium coccidia in selected organs and the abomasum where lifecycle stages would be expected during an infection (Pospischil et al. 1987, Anderson 1987, Kváč and Vítovec 2003).

Although in the present study a limited number of animals was tested, it can be concluded that the isolate used was noninfective for lambs at 4 months of age.

This work was supported by the grant of the Grant Agency of the Academy of Sciences of the Czech Republic (project no. 6022006) and by the grant of the Ministry of Education, Youth and Sports of the Czech Republic (project MSM 1222 00002). The authors thank Suschjainder Singh for English language corrections of a draft of the manuscript.

\section{References}

ANDERSON B.C. 1987: Abomasal cryptosporidiosis in cattle Vet. Pathol. 24: 235-238.

ANDERSON B.C. 1991: Experimental infection in mice of Cryptosporidium muris isolated from a camel. J. Protozool. 38: $16-17 \mathrm{~S}$.

CHALMERS R.M., ELWIN K., REILLY W.J., IRVINE H., THOMAS A.L., HUNTER P.R. 2002: Cryptosporidium in farmed animals: the detection of a novel isolate in sheep. Int. J. Parasitol. 32: 21-26.

DOWD S.E., PILLAI S.D. 1997: A rapid viability assay for Cryptosporidium oocysts and Giardia cysts for use in conjunction with indirect fluorescent antibody detection. Can. J. Microbiol. 43: 658-662.

ENEMARK H.L., AHRENS P., LOWERY C.J., THAMSBORG S.M., ENEMARK J.M.D., BILLE-HANSEN V., LIND P. 2002: Cryptosporidium andersoni from a Danish cattle herd: identification and preliminary characterisation. Vet. Parasitol. 107: 37-49.

FAYER R., PHILLIPS L., ANDERSON B.C., BUSH M. 1991: Chronic cryptosporidiosis in a Bactrian camel (Camelus bactrianus). J. Zoo Wildl. Med. 22: 228-232.

GUYOT K., FOLLET-DUMOULIN A., LELIEVRE E., SARFATI C., RABODONIRINA M., NEVEZ G., CAILLIEZ J.C., CAMUS D., DEI-CAS E. 2001: Molecular characterisa- tion of Cryptosporidium isolates obtained from humans in France. J. Clin. Microbiol. 39: 3472-3480.

HENRIKSEN S.A., POHLENZ J.F.L. 1981: Staining of cryptosporidia by modified Ziehl-Neelsen technique. Acta Vet. Scand. 22: 594-596.

KOUDELA B., MODRÝ D., VÍTOVEC J. 1998: Infectivity of Cryptosporidium muris isolated from cattle. Vet. Parasitol. 76: $181-188$.

KVÁČ M., VÍTOVEC J. 2003: Prevalence and pathogenicity of Cryptosporidium andersoni in one herd of beef cattle. J. Vet. Med. B 50: 451-457.

LINDSAY D.S., UPTON S.J., OWENS D.S., MORGAN U.M., MEAD J.R., BLAGBURN B.L. 2000: Cryptosporidium andersoni $\mathrm{n}$. sp. (Apicomplexa: Cryptosporidiidae) from cattle, Bos taurus. J. Eukaryot. Microbiol. 47: 91-95.

MEUTIN D.J., van KRUININGEN H.J., KEIN D.H. 1974: Cryptosporidiosis in a calf. J. Am. Vet. Med. Assoc. 165: 914-917.

MILÁČEK P., VÍTOVEC J. 1985: Differential staining of cryptosporidia by aniline carbol-methyl violet and tartrazine in smears from faeces and scrapings of intestinal mucosa. Folia Parasitol. 32: 50.

POSPISCHIL A., STIGLMAIR-HERB M.T., von HEGEL G., WIESNER H. 1987: Abomasal cryptosporidiosis in mountain gazelles. Vet. Rec. 17: 379-380.

RYAN U., XIAO L., READ C., ZHOU L., LAL A.A., PAVLÁSEK I. 2003: Identification of novel Cryptosporidium genotypes from the Czech Republic. Appl. Environ. Microbiol. 69: 4302-4307.

SATOH M., HIKOSAKA K., SASAKI T., SUYAMA Y., YANAI T., OHTA M., NAKAI Y. 2003: Characteristics of novel type of bovine Cryptosporidium andersoni. Appl. Environ. Microbiol. 69: 691-692.

SRÉTER T., EGYED Z., SZÉLL Z., KOVÁCS G., NIKOLAUSZ M., MÁRIALIGETI K., VARGA I. 2000: Morphologic, host specificity, and genetic characterization of a European Cryptosporidium andersoni isolate. J. Parasitol. 86: 1244-1249.

Received: 27 November 2003

Accepted: 22 March 2004 